in vivo $34: 2891-2896(2020)$

doi:10.21873/invivo.12117

\title{
Prediction of Therapeutic Effects from One Course of TPF Chemotherapy for Advanced Hypopharyngeal Laryngeal Cancer
}

\author{
RYO MARUYAMA ${ }^{1}$, ISAKU OKAMOTO ${ }^{1}$, HIROKI SATO ${ }^{1}$, YASUAKI KATSUBE ${ }^{1}$, \\ TAKAHITO KONDO ${ }^{2}$ and KIYOAKI TSUKAHARA ${ }^{1}$ \\ ${ }^{1}$ Department of Otorhinolaryngology, Head and Neck Surgery, Tokyo Medical University, Tokyo, Japan; \\ ${ }^{2}$ Department of Otorhinolaryngology, Head and Neck Surgery, \\ Tokyo Medical University Hachioji Medical Center, Tokyo, Japan
}

\begin{abstract}
Background: In head and neck cancer, docetaxel, cisplatin and 5-fluorouracil (TPF) is often given in two or three cycles. The purpose of this study was to perform single-cycle TPF for chemoselection in patients with advanced hypopharyngeal laryngeal cancer. Patients and Methods: The study included 56 patients with stage III/IV advanced hypopharyngeal/laryngeal squamous cell carcinoma. The primary endpoint was progression-free survival (PFS), and secondary endpoints were overall survival (OS), TPF response rate, laryngeal sparing, and grade 3 or more adverse events. Results: The median PFS was 34.8 months. The median OS was not evaluable. The response rate was $71 \%$. The median laryngeal preservation period was not estimable. Grade 3 or 4 adverse events were reported in 46 patients. Conclusion: PFS rate in this study may have been improved by selecting surgical treatment for patients for whom chemoradiotherapy seemed less effective. One cycle of TPF in induction chemotherapy appeared effective for chemoselection.
\end{abstract}

Laryngeal preservation is an important factor in deciding the treatment strategy for advanced hypopharyngeal laryngeal cancer. Since the effectiveness of concurrent chemoradiotherapy (CCRT) was reported (1-3), this method has become the main approach to the treatment of advanced laryngeal cancer. On the

This article is freely accessible online.

Correspondence to: Isaku Okamoto, MD, Ph.D., Department of Otorhinolaryngology, Head and Neck Surgery, Tokyo Medical University, 6-7-1 Nishishinjuku, Shinjuku-ku, Tokyo 160-0023, Japan. Fax: +81 333469275, Tel: +81 333426111, E-mail: isaku@tokyomed.ac.jp

Key Words: Advanced hypopharyngeal laryngeal cancer, chemoselection, induction chemotherapy, TPF chemotherapy. other hand, overall treatment outcomes were found to be worse in the 1990s, when mainly CCRT was used, than in the 1980s when the approach was primarily surgical (4). This indicates that many advanced hypopharyngeal and laryngeal cancers are difficult to cure using CCRT. In addition, long-term follow-up of the RTOG91-11 study showed that CCRT has improved laryngeal preservation but not overall survival (OS) (5).

In head and neck cancer, the current standard regimen for induction chemotherapy (ICT) is TPF chemotherapy, comprising docetaxel, cisplatin and 5-fluorouracil $(6,7)$. TPF chemotherapy is often given in two or three cycles. The National Comprehensive Cancer Network (NCCN) guidelines state that TPF chemotherapy is category 1 if ICT is chosen (8). ICT with TPF chemotherapy had been expected to improve OS rates but all except one (9) of the randomized controlled trials conducted regarding this treatment to date have ruled out its contribution to improving OS (10-12). The purpose of ICT, other than improving survival, is to predict the effects of CCRT. This idea of such so-called chemoselection is that radiotherapy may be more effective for cancer that responds to chemotherapy. For chemoselection, some reports have used cisplatin and 5fluorouracil for one cycle before considering treatment strategies $(13,14)$. However, no reports appear to have described chemoselection with a single cycle of TPF chemotherapy, which is the current standard regimen. The purpose of this investigation was to perform one cycle of TPF chemotherapy for advanced hypopharyngeal laryngeal cancer for chemoselection, and to then examine the adequacy of subsequent treatment according to progression-free survival (PFS) from the start of the second treatment.

\section{Patients and Methods}

Patients. Participants comprised 61 patients $<75$ years old with stage III/IV advanced hypopharyngeal or laryngeal squamous cell carcinoma without distant metastases treated between August 1, 2014 and August 31, 2019 at either Tokyo Medical University Hospital or Tokyo Medical University Hachioji Medical Center. Staging was determined 
using the seventh edition of the Union for International Cancer Control (UICC) classification (15). We explained to each patient that they needed surgery or CCRT. The surgical procedure for the primary tumor was total pharyngo-laryngo-esophagectomy (TPLE), total pharyngo-laryngotomy (TPL), or total laryngotomy (TL). We explained our policy of performing one course of TPF chemotherapy as chemoselection when the decision on whether to use surgery or concomitant chemoradiotherapy is difficult. Three patients underwent radiotherapy with cisplatin or cetuximab after declining surgery. Five patients were excluded: one patient declined treatment evaluation after TPF chemotherapy, and refused curative treatment; another discontinued treatment after the first day of TPF chemotherapy; one patient discontinued consultation immediately after completion of curative cetuximab radiotherapy; and a further two patients requested treatment at another hospital after TPF chemotherapy. These five patients were excluded and the remaining 56 patients were included for analysis in the study.

Administration of TPF. For TPF chemotherapy, cisplatin and docetaxel were intravenously infused at a dose of $60 \mathrm{mg} / \mathrm{m}^{2}$ each on day 1 and 5 -fluorouracil was intravenously infused at a dose of $600 \mathrm{mg} / \mathrm{m}^{2}$ on days 1-5 for $24 \mathrm{~h}$. Computed tomography was performed between 21 and 28 days after starting TPF chemotherapy, and therapeutic effects were evaluated by a radiological specialist according to RECIST version 1.1 guidelines (16). Patients showing complete response (CR) or partial response (PR) received concomitant chemoradiotherapy, while patients with stable disease (SD) or progressive disease (PD) underwent TPLE, TPL or TL. Free-flap reconstruction was recommended for cases requiring bilateral neck dissection and reconstructive surgery. Finally, a radical treatment policy was decided according to the wishes of the patient.

Administration of CCRT. When performing CCRT for laryngeal preservation purposes, the radiation dose was $2 \mathrm{~Gy} / \mathrm{day}$ and the expected total dose was 66-70 Gy. In principle, cetuximab was used in combination as the chemotherapeutic component. When interstitial pneumonia or pulmonary emphysema was detected on imaging before treatment, cetuximab was considered a high-risk option (17), and cisplatin was instead used in combination. CCRT with cisplatin was performed after neck dissection when cervical lymph node metastasis with extranodal invasion was observed.

Radiochemotherapy with cetuximab was based on the Bonner test (18). The first dose of cetuximab was $400 \mathrm{mg} / \mathrm{m}^{2} /$ day, and subsequent doses were $250 \mathrm{mg} / \mathrm{m}^{2} /$ day once a week. On postoperative CCRT, cisplatin was administered three times, on days 1,22 , and 43 of radiotherapy. The first dose of cisplatin was at $80 \mathrm{mg} / \mathrm{m}^{2}$. Cisplatin was reduced to an $80 \%$ dose (to $64 \mathrm{mg} / \mathrm{m}^{2}$ ) when the estimated glomerular filtration rate (eGFR) was $\geq 40 \mathrm{ml} / \mathrm{min} / 1.73 \mathrm{~m}^{2}$ but $<60 \mathrm{ml} / \mathrm{min} / 1.73 \mathrm{~m}^{2}$, or there was a grade 3 adverse event. Cisplatin was discontinued for eGFR $<40 \mathrm{ml} / \mathrm{min} / 1.73 \mathrm{~m}^{2}$ or if an adverse event of grade 4 or more was identified. Administration of cisplatin during TPF chemotherapy or CCRT was provided with hydration to result in $>3,000 \mathrm{ml} /$ day of urine. On days 1-3 of administration, $10 \mathrm{mEq}$ of magnesium was administered. For one patient who underwent reconstruction with a free jejunal flap, radiotherapy was performed in 28 fractions at a dose of $1.8 \mathrm{~Gy}$, for a total dose of $50.4 \mathrm{~Gy}$. In other cases, the dose was administered in 30 fractions of $2 \mathrm{~Gy}$, for a total dose of $60 \mathrm{~Gy}$.

Staging method. TNM classification was performed using Union for International Cancer Control version 7 criteria (15).
Table I. Background characteristics of patients.

\begin{tabular}{llcr}
\hline Characteristic & & $\mathrm{n}$ & $\%$ \\
\hline Age, years & Mean & 65 & \\
& Median (range) & $66(39-75)$ & \\
Gender & Male & 52 & 96 \\
& Female & 4 & 4 \\
Smoking history & Non-smoker & 8 & 14 \\
& Smoker & 45 & 80 \\
History of alcohol use & Missing & 3 & 5 \\
& Non-drinker & 5 & 9 \\
Histology & Drinker & 48 & 86 \\
Primary tumor site & Missing & 3 & 5 \\
& Squamous cell carcinoma & 56 & 100 \\
& Hypopharynx & 48 & 86 \\
T Category & Larynx & & \\
& Glottic & 5 & 9 \\
& Supraglottic & 3 & 5 \\
& 1 & 1 & 2 \\
N Category & 2 & 12 & 21 \\
& 3 & 14 & 25 \\
& 4 & 29 & 52 \\
& 0 & 10 & 18 \\
M Category & 1 & 8 & 14 \\
UICC stage & 2 & 37 & 66 \\
& 3 & 1 & 2 \\
& 0 & 56 & 100 \\
& 1 & 0 & 0 \\
& I & 0 & 0 \\
& II & 0 & 0 \\
& III & 10 & 18 \\
& IV & 46 & 82 \\
\hline
\end{tabular}

Study endpoints. The primary endpoint was PFS, and secondary endpoints were OS, response rate to TPF therapy, laryngeal preservation, and frequency of adverse events of grade 3 or more. PFS and OS were assessed using Kaplan-Meier methods. Statistical analysis was carried out using the log-rank test and values of $p<0.05$ were taken to indicate a significant difference. Adverse events were evaluated using Common Toxicity Criteria for Adverse Events (CTCAE) version 4.0 (19).

PFS was determined as the period from the second treatment to the determination of SD or PD after the second treatment or at the end of the study period, whichever came first. OS was set as the period from the second treatment to death or study period, whichever came first.

Statistical analysis and ethics. All statistical analyses were performed using EZR (Saitama Medical Center, Jichi Medical University, Saitama, Japan), a graphical user interface for the $\mathrm{R}$ software environment for statistical computing and graphics (The R Foundation for Statistical Computing, Vienna, Austria). EZR is a modified version of R Commander designed to add statistical functions frequently used in biostatistics (20). This study was approved by the Ethics Committees of Tokyo Medical University and Tokyo Medical University Hachioji Medical Center (approval no. T2019-0195). This study was conducted in accordance with the Declaration of Helsinki and written consent for treatment was obtained from all patients. 


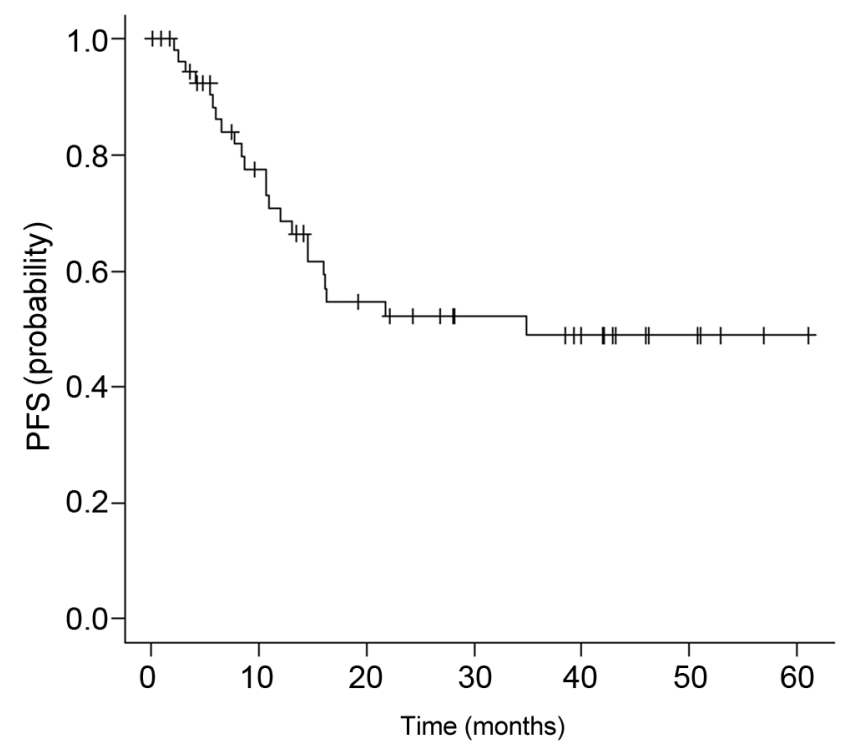

Figure 1. Kaplan-Meier survival curves for progression-free survival (PFS) after second treatment; that is, after docetaxel, cisplatin and 5fluorouracil chemotherapy. Median PFS for all patients was 34.8 months (95\% confidence intervaI=14.4 months-not estimable). The 2year PFS rate was $52.1 \%$ (95\% confidence intervaI=24.6-55.6\%), and the 3-year PFS rate was $48.9 \%$ (95\% confidence intervaI=33.2-62.8\%).

\section{Results}

Background characteristics of patients. Background characteristics are shown in Table I. Patients comprised 52 men and four women, ranging in age from 39 to 75 years ( mean $=65$ years; median $=66$ years). The underlying pathology was hypopharyngeal cancer in 48 cases, glottic laryngeal cancer in 5 cases, and supraglottic laryngeal cancer in 3 cases. Stage classification at the initial consultation was stage III in 10 cases and stage IV in 46 cases. Classification was T3 or higher in the majority of cases $(77 \%)$, and N2 or higher in most (71\%). Histopathological type was squamous cell carcinoma in all cases.

PFS. Results for PFS are shown in Figure 1. The median PFS was 34.8 months [ $95 \%$ confidence interval $(\mathrm{CI})=14.4$ monthsnot estimable]. PFS rates at 2 and 3 years were $52.1 \%(95 \%$ $\mathrm{CI}=36.6-65.5 \%)$ and $48.9 \% \quad(95 \% \quad \mathrm{CI}=33.2-62.8 \%)$, respectively.

OS. Results for OS are shown in Figure 2. The median OS was not evaluable. Two- and 3-year OS rates were $81.5 \%$ $(95 \% \mathrm{CI}=66.3-90.3 \%)$ and $78.1 \%(95 \% \mathrm{CI}=61.7-88.1 \%)$, respectively.

Response. Tumor response was CR in one case, PR in 39, SD in 12 , and $\mathrm{PD}$ in four. The response rate was $71 \%$.

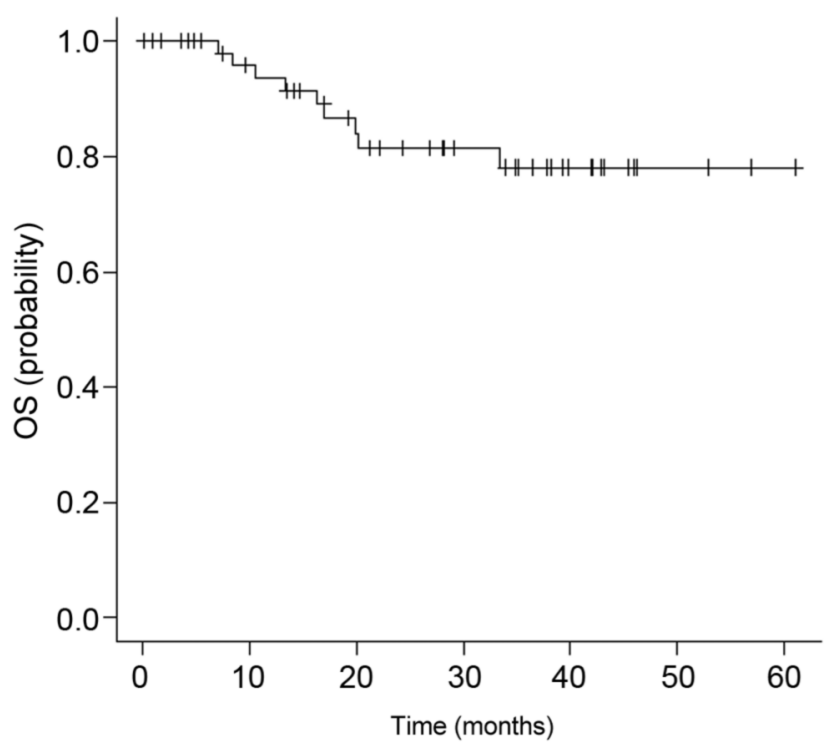

Figure 2. Kaplan-Meier survival curves for overall survival (OS) within the study period. Median OS was not estimable. The 2-year OS rate was $81.5 \%$ (95\% confidence intervaI $=66.3-90.3 \%)$, and the 3 -year OS rate was $78.1 \%$ (95\% confidence intervaI=61.7-88.1\%).

Laryngeal preservation. Results for laryngeal preservation are shown in Figure 3. Laryngectomy was performed in 18 out of the 56 cases. The median laryngeal preservation period was not estimable. The laryngeal preservation rate during the study period was $68 \%$. Two- and 3-year laryngeal preservation rates were $65.4 \%(95 \% \mathrm{CI}=50.6-76.7 \%)$ and $65.4 \%(95 \% \mathrm{CI}=50.6-$ $76.7 \%)$, respectively.

Grade 3 or more adverse events. Adverse events are shown in Table II. Grade 3 or 4 adverse events were reported in 46 patients $(82 \%)$ but no grade 5 events were identified. The identified events comprised reduced white blood cell count in 39 cases (70\%), reduced neutrophil count in 43 (78\%), hyponatremia in $10(18 \%)$, and anorexia (2\%), increased creatinine level (2\%), hypokalemia (2\%), and reduced hemoglobin level $(2 \%)$ in one each. Febrile neutropenia was observed in 18 patients $(32 \%)$.

\section{Discussion}

ICT with TPF has been suggested to be effective for chemoselection. However, no reports have described the efficacy of chemoselection using single-cycle TPF. This study provided one cycle of TPF as chemoselection for advanced hypopharyngeal or laryngeal cancer, and examined the adequacy of treatment using PFS from the second treatment. The median PFS after chemoselection was 34.8 months. Two- and 3-year 


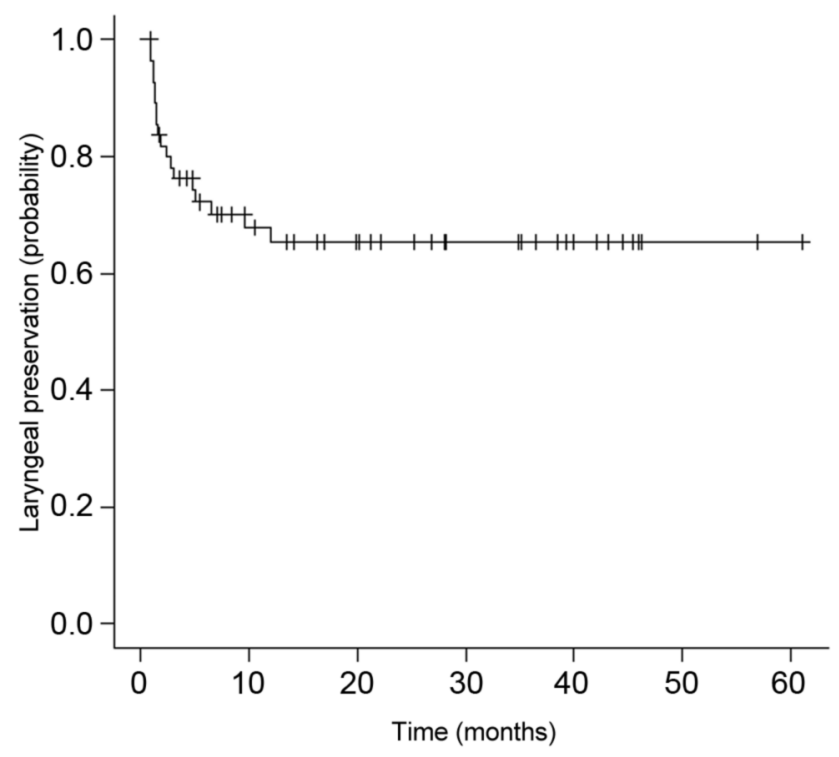

Figure 3. Kaplan-Meier survival curves for laryngeal preservation within the study period. Median duration of laryngeal preservation for all patients was not estimable. The 2-year laryngeal preservation rate was $65.4 \%$ (95\% confidence intervaI $=50.6-76.7 \%)$, and the 3-year laryngeal preservation rate was $65.4 \%$ (95\% confidence intervaI $=50.6-76.7 \%$ ).

PFS rates were $52 \%$ and $49 \%$, respectively. Two- and 3-year survival rates were $82 \%$ and $78 \%$, respectively. PFS may have been improved by selecting surgical treatment for patients whom radiochemotherapy seemed to be less effective.

We believe that prolonging PFS involves selecting the treatment most appropriate for the patient by chemoselection. In the present study, we considered that PFS might have been further extended if surgery had been selected for patients who had selected chemotherapy according to their wishes.

From the OS, mortality may be increased in cases that did not respond to TPF and if surgery was not or could not be selected. The response rate was $71 \%$, and the 3-year laryngeal preservation rate was $65.4 \%$. In other words, one course of TPF chemotherapy appears to be appropriate for chemoselection of second-line treatment.

Many adverse events were encountered but no patient died. However, $32 \%$ of cases showed febrile neutropenia and this aspect may need close control during TPF.

We generally use cetuximab in combination with radiotherapy after ICT. The trial by Bonner et al. showed that compared with radiotherapy alone for locally advanced head and neck cancer, radiotherapy combined with cetuximab improved local control and reduced mortality, without increasing adverse events associated with radiotherapy (18). We therefore compared results from the present study with PFS in that trial. In their trial, median PFS was 17.1 months for patients treated with radiotherapy and cetuximab, and 2- and 3-year PFS rates were $46 \%$ and $42 \%$, respectively. The median PFS in our study was
Table II. Adverse events experienced by study patients treated with docetaxel, cisplatin and 5-fluorouracil chemotherapy.

\begin{tabular}{|c|c|c|c|c|}
\hline \multirow[b]{2}{*}{ Adverse event } & \multicolumn{4}{|c|}{ Grade, n (\%) } \\
\hline & 3 & 4 & 5 & $3-5$ \\
\hline $\begin{array}{l}\text { Reduced white blood } \\
\text { cell count }\end{array}$ & $29(51.8 \%)$ & $10(17.9 \%)$ & 0 & $39(69.6 \%)$ \\
\hline $\begin{array}{l}\text { Reduced neutrophil } \\
\text { count }\end{array}$ & $18(32.1 \%)$ & $25(44.6 \%)$ & 0 & $43(76.8 \%)$ \\
\hline Hyponatremia & $8(14.3 \%)$ & $2(3.6 \%)$ & 0 & $10(17.9 \%)$ \\
\hline Anorexia & $1(1.8 \%)$ & 0 & 0 & $1(1.8 \%)$ \\
\hline Creatinine increased & $1(1.8 \%)$ & 0 & 0 & $1(1.8 \%)$ \\
\hline Hypokalemia & 0 & $1(1.8 \%)$ & 0 & $1(1.8 \%)$ \\
\hline Reduced hemoglobin & $1(1.8 \%)$ & 0 & 0 & $1(1.8 \%)$ \\
\hline Febrile neutropenia & $18(32.1 \%)$ & 0 & 0 & $18(32.1 \%)$ \\
\hline
\end{tabular}

34.8 months, better than in the trial of Bonner et al. Similarly, 2- and 3-year PFS rates were $52 \%$ and $49 \%$, respectively, again better. This suggests that for chemoselected cases in which the effects of radiochemotherapy are considered poor, selection of surgical treatment may extend the PFS.

The GORTEC 2000-01 trial, as the basis for the standard regimen for TPF chemotherapy, had a 3-year OS rate of $60 \%$ in the group receiving three cycles of TPF chemotherapy (21). We administered one cycle of TPF chemotherapy. Two- and 3-year OS rates were $82 \%$ and $78 \%$, respectively. Single-cycle TPF for chemoselection appears to be effective. In recent years, trials of single-cycle ICT have been performed to determine surgical indications for patients with resectable locally advanced head and neck cancer. In 2006, Urba et al. performed ICT with cisplatin and 5-fluorouracil in 97 patients with advanced head and neck cancer. When the tumor reduction rate was $50 \%$ or more, two cycles of cisplatin and 5-fluorouracil were performed after CCRT with cisplatin, and when the rate was $<50 \%$ (13), radiotherapy was performed after surgery, yielding a 3-year OS rate of $85 \%$. In 2016, Popovtzer et al. provided ICT with TPF for 26 cases of locally advanced head and neck cancer. At the end of one cycle, the response rate was evaluated by positron emission tomography/computed tomography, and chemoradiotherapy was performed for patients with $50 \%$ or more tumor reduction, while laryngectomy was performed for patients with tumor reduction $<50 \%$. The 2 -year OS rate was $80 \%$ (22). Among studies using one cycle of ICT, some reports have described administration of radiochemotherapy to patients with tumor shrinkage rates of $50 \%$ or higher $(13,22)$. The OS rate in our study was similar to the rates in those reports. In this study, chemoradiotherapy was provided for cases showing tumor shrinkage $\geq 30 \%$. Chemoradiotherapy with cetuximab was thus likely to be selected in this study. However, despite the ease of selection, OS rates were about the same, suggesting that the criteria for ICT as chemoselection were reasonable. 
The most common standard dose regimen for TPF chemotherapy is three cycles of cisplatin at $75 \mathrm{mg} / \mathrm{m}^{2}$, docetaxel at $75 \mathrm{mg} / \mathrm{m}^{2}$, and 5-fluorouracil at $750 \mathrm{mg} / \mathrm{m}^{2}$ every 3 weeks, as per the TAX323 trial (6). The response rate to three cycles of standard TPF chemotherapy is reportedly around $70 \%$ $(6,7)$, and the response rate for one course of TPF chemotherapy in this study was $71 \%$. These response rates are basically the same. On the other hand, only one CR was seen in our cohort. Some patients with PR might have further improved to CR with 2-3 cycles of TPF. However, if additional treatment is delayed until completion of three cycles of TPF, treatment options become narrowed due to deterioration of the patient's general condition. Since the aim of chemoselection is to predict the effects of radiotherapy as curative treatment, we do not consider administration of chemotherapy until CR as necessary. Administering three cycles at standard doses results in a $2-5 \%$ mortality rate according to treatment results in Western populations (6). Grade 3/4 events accounted for $76.9 \%$ of adverse events in the TAX323 (6) and 83\% in TAX324 (7) trials. Except for one study (9), no prognosis-enhancing effects were observed. In our study, the dose of TPF chemotherapy was $80 \%$ of that in TAX323 (6), with cisplatin and docetaxel at $60 \mathrm{mg} / \mathrm{m}^{2}$ each, and 5 -fluorouracil at $600 \mathrm{mg} / \mathrm{m}^{2}$, following the Japanese standard regimen for CCRT. In our case, even at $80 \%$ of the TAX323 doses, grade $3 / 4$ adverse events were observed in $82 \%$ of patients, comparable to TAX323 and TAX324. In particular, $32 \%$ of events were febrile neutropenia, a potentially fatal complication. This was higher than the $5.2 \%$ reported in TAX323 and 12\% in TAX324. Fortunately, none of our patients died due to treatment, but even $80 \%$ of the dose used in TAX323 cannot be seen as necessarily safe for Japanese populations. Therefore, when additional treatment is performed after completion of three cycles of standard TPF chemotherapy, treatment options seem highly likely to be narrowed due to deterioration in the patient's general condition.

The laryngeal preservation rate was $70 \%$ in the GORTEC 2000-01 (21). Urba et al. reported a 3-year laryngeal preservation rate of $70 \%$ (13), while Popovtzer et al. reported a 2-year laryngeal preservation rate of $83 \%$ (22). In the present study, the laryngeal preservation rate was $65.4 \%$ at both 2 and 3 years, slightly lower than those studies. This was a result of selecting appropriate surgical treatment for patients in whom chemoradiation was considered likely to be less effective. To increase laryngeal preservation, only surgical treatment with laryngectomy is necessary. Indeed, while reporting on laryngeal cancer, Hoffman et al. noted a decrease in survival of patients with laryngeal cancer with increasing CCRT in the United States between 1985 and 2001 (4). This suggests that reduced survival rates for patients with T3N0M0 laryngeal carcinoma may be attributable to reduced rates of surgery.

In this study, we performed one cycle of TPF chemotherapy as chemoselection for advanced hypopharyngeal and laryngeal cancer and examined the validity of this treatment method.
Chemoselection suggests that patients for whom radiochemotherapy may be less effective can maintain good PFS by choosing surgery. Extension of PFS also leads to extension of OS. Rates of response to TPF chemotherapy are similar for one and three cycles, and one cycle is thus considered appropriate for the purposes of chemoselection.

Effective selection of treatments, not just TPF, contributes to PFS and OS. In the field of immunotherapy for recurrent and metastatic head and neck cancer, research into factors predicting therapeutic effects has been actively pursued. As future tasks, increasing the number of cases in a multicenter prospective study and examining the utility of single-cycle TPF chemotherapy as chemoselection appear desirable.

\section{Conclusion}

Although direct comparison was not possible, our results were better than those reported in the literature. One cycle of TPF chemotherapy as ICT was effective for chemoselection and PFS may have been improved by selecting surgical treatment for patients who seemed to gain less effect from chemoradiotherapy.

\section{Conflicts of Interest}

The Authors report no conflicts of interest.

\section{Authors' Contributions}

RM, IO, HS and KT designed the study. RM wrote the main text and prepared the Figure. RM, IO, HS, YK, KT and TK were involved in data collection. RM and IO performed the analysis. All Authors discussed the results of the study, made comments on the article, and gave final approval of the version to be published.

\section{References}

1 Forastiere AA, Goepfert H, Maor M, Pajak TF, Weber R, Morrison W, Glisson B, Trotti A, Ridge JA, Chao C, Peters G, Lee DJ, Leaf A, Ensley J and Cooper J: Concurrent chemotherapy and radiotherapy for organ preservation in advanced laryngeal cancer. $\mathrm{N}$ Engl J Med 349(22): 2091-2098, 2003. PMID: 14645636. DOI: 10.1056/NEJMoa031317

2 Pignon JP, Bourhis J, Domenge C and Designe L: Chemotherapy added to locoregional treatment for head and neck squamous-cell carcinoma: Three meta-analyses of updated individual data. $\mathrm{MACH}-$ NC Collaborative Group. Meta-analysis of chemotherapy on head and neck cancer. Lancet 355(9208): 949-955, 2000. PMID: 10768432 .

3 Pignon JP, le Maitre A, Maillard E, Bourhis J and Group M-NC: Meta-analysis of chemotherapy in head and neck cancer (MACH$\mathrm{NC}$ ): An update on 93 randomised trials and 17,346 patients. Radiother Oncol 92(1): 4-14, 2009. PMID: 19446902. DOI: 10.1016/j.radonc.2009.04.014

4 Hoffman HT, Porter K, Karnell LH, Cooper JS, Weber RS, Langer CJ, Ang KK, Gay G, Stewart A and Robinson RA: Laryngeal cancer in the United States: Changes in demographics, patterns of care, and 
survival. Laryngoscope 116(9 Pt 2 Suppl 111): 1-13, 2006. PMID: 16946667. DOI: $10.1097 / 01$ mlg.0000236095.97947.26

5 Forastiere AA, Zhang Q, Weber RS, Maor MH, Goepfert H, Pajak TF, Morrison W, Glisson B, Trotti A, Ridge JA, Thorstad W, Wagner H, Ensley JF and Cooper JS: Long-term results of RTOG 91-11: A comparison of three nonsurgical treatment strategies to preserve the larynx in patients with locally advanced larynx cancer. J Clin Oncol 31(7): 845-852, 2013. PMID: 23182993. DOI: 10.1200/JCO.2012.43.6097

6 Vermorken JB, Remenar E, van Herpen C, Gorlia T, Mesia R, Degardin M, Stewart JS, Jelic S, Betka J, Preiss JH, van den Weyngaert D, Awada A, Cupissol D, Kienzer HR, Rey A, Desaunois I, Bernier J and Lefebvre JL: Cisplatin, fluorouracil, and docetaxel in unresectable head and neck cancer. N Engl J Med 357(17): 16951704, 2007. PMID: 17960012. DOI: 10.1056/NEJMoa071028

7 Posner MR, Hershock DM, Blajman CR, Mickiewicz E, Winquist E, Gorbounova V, Tjulandin S, Shin DM, Cullen K, Ervin TJ, Murphy BA, Raez LE, Cohen RB, Spaulding M, Tishler RB, Roth B, Viroglio Rdel C, Venkatesan V, Romanov I, Agarwala S, Harter KW, Dugan M, Cmelak A, Markoe AM, Read PW, Steinbrenner L, Colevas AD, Norris CM, Jr. and Haddad RI: Cisplatin and fluorouracil alone or with docetaxel in head and neck cancer. N Engl J Med 357(17): 1705-1715, 2007. PMID: 17960013. DOI: 10.1056/NEJMoa070956

8 National Comprehensive Cancer Network (NCCN): Clinical practice guidelines in oncology, head and neck cancers (version 1.2020). Available at: https://www.nccn.org/professionals/ physician_gls/pdf/head-and-neck_blocks.pdf [Last accessed on May 22, 2020]

9 Ghi MG, Paccagnella A, Ferrari D, Foa P, Alterio D, Codecà C, Nolè F, Verri E, Orecchia R, Morelli F, Parisi S, Mastromauro C, Mione CA, Rossetto C, Polsinelli M, Koussis H, Loreggian L, Bonetti A, Campostrini F, Azzarello G, D’Ambrosio C, Bertoni F, Casanova C, Emiliani E, Guaraldi M, Bunkheila F, Bidoli P, Niespolo RM, Gava A, Massa E, Frattegiani A, Valduga F, Pieri G, Cipani T, Da Corte D, Chiappa F and Rulli E: Induction TPF followed by concomitant treatment versus concomitant treatment alone in locally advanced head and neck cancer. A phase II-III trial. Ann Oncol 28(9): 22062212, 2017. PMID: 28911070 . DOI: $10.1093 /$ annonc/mdx 299

10 Haddad R, O’Neill A, Rabinowits G, Tishler R, Khuri F, Adkins D, Clark J, Sarlis N, Lorch J, Beitler JJ, Limaye S, Riley S and Posner M: Induction chemotherapy followed by concurrent chemoradiotherapy (sequential chemoradiotherapy) versus concurrent chemoradiotherapy alone in locally advanced head and neck cancer (PARADIGM): A randomised phase 3 trial. Lancet Oncol 14(3): 257-264, 2013. PMID: 23414589. DOI: 10.1016/S 1470-2045(13)70011-1

11 Cohen EE, Karrison TG, Kocherginsky M, Mueller J, Egan R, Huang CH, Brockstein BE, Agulnik MB, Mittal BB, Yunus F, Samant S, Raez LE, Mehra R, Kumar P, Ondrey F, Marchand P, Braegas B, Seiwert TY, Villaflor VM, Haraf DJ and Vokes EE: Phase III randomized trial of induction chemotherapy in patients with N2 or N3 locally advanced head and neck cancer. J Clin Oncol 32(25): 2735-2743, 2014. PMID: 25049329. DOI: 10.1200/JCO.2013.54.6309

12 Hitt R, Grau JJ, López-Pousa A, Berrocal A, García-Girón C, Irigoyen A, Sastre J, Martínez-Trufero J, Brandariz Castelo JA, Verger E and Cruz-Hernández JJ: A randomized phase III trial comparing induction chemotherapy followed by chemoradiotherapy versus chemoradiotherapy alone as treatment of unresectable head and neck cancer. Ann Oncol 25(1): 216-225, 2014. PMID: 24256848. DOI: $10.1093 / \mathrm{annonc} / \mathrm{mdt} 461$

13 Urba S, Wolf G, Eisbruch A, Worden F, Lee J, Bradford C, Teknos T, Chepeha D, Prince M, Hogikyan N and Taylor J: Single-cycle induction chemotherapy selects patients with advanced laryngeal cancer for combined chemoradiation: A new treatment paradigm. J Clin Oncol 24(4): 593-598, 2006. PMID: 16380415. DOI: 10.1200/JCO.2005.01.2047

14 Vainshtein JM, Wu VF, Spector ME, Bradford CR, Wolf GT and Worden FP: Chemoselection: A paradigm for optimization of organ preservation in locally advanced larynx cancer. Expert Rev Anticancer Ther 13(9): 1053-1064, 2013. PMID: 24053204. DOI: $10.1586 / 14737140.2013 .829646$

15 Sobin LH, Gospodarowicz MK and Wittekind C: International union against cancer (UICC) TNM classification of malignant tumours, $7^{\text {th }}$ edition. New York: Wiley-Liss, 2010.

16 Eisenhauer EA, Therasse P, Bogaerts J, Schwartz LH, Sargent D, Ford R, Dancey J, Arbuck S, Gwyther S, Mooney M, Rubinstein L, Shankar L, Dodd L, Kaplan R, Lacombe D and Verweij J: New response evaluation criteria in solid tumours: Revised RECIST guideline (version 1.1). Eur J Cancer 45(2): 228-247, 2009. PMID: 19097774. DOI: 10.1016/j.ejca.2008.10.026

17 Okamoto I, Tsukahara K, Sato H, Motohashi R, Yunaiyama D and Shimizu A: Mild pulmonary emphysema a risk factor for interstitial lung disease when using cetuximab for squamous cell carcinoma of the head and neck. Acta Otolaryngol 137(12): 1288-1291, 2017. PMID: 28741444. DOI: 10.1080/00016489.2017.1355566

18 Bonner JA, Harari PM, Giralt J, Azarnia N, Shin DM, Cohen RB, Jones CU, Sur R, Raben D, Jassem J, Ove R, Kies MS, Baselga J, Youssoufian H, Amellal N, Rowinsky EK and Ang KK: Radiotherapy plus cetuximab for squamous-cell carcinoma of the head and neck. N Engl J Med 354(6): 567-578, 2006. PMID: 16467544. DOI: 10.1056/NEJMoa053422

19 National Cancer Institute. Common Terminology Criteria for Adverse Events v.3.0 and v.4.0 (CTCAE). Available at: http://ctep.cancer.gov/protocolDevelopment/electronic_applications/c tc.htm [Last accessed on Aug 29, 2019]

20 Kanda Y: Investigation of the freely available easy-to-use software 'EZR' for medical statistics. Bone Marrow Transplant 48(3): 452458, 2013. PMID: 23208313. DOI: 10.1038/bmt.2012.244

21 Pointreau Y, Garaud P, Chapet S, Sire C, Tuchais C, Tortochaux J, Faivre S, Guerrif S, Alfonsi M and Calais G: Randomized trial of induction chemotherapy with cisplatin and 5-fluorouracil with or without docetaxel for larynx preservation. J Natl Cancer Inst 101(7): 498-506, 2009. PMID: 19318632 DOI: 10.1093/jnci/djp007

22 Popovtzer A, Burnstein H, Stemmer S, Limon D, Hili O, Bachar G, Sopov V, Feinmesser R, Groshar D and Shvero J: Phase II organpreservation trial: Concurrent cisplatin and radiotherapy for advanced laryngeal cancer after response to docetaxel, cisplatin, and 5-fluorouracil-based induction chemotherapy. Head Neck 39(2): 227233, 2017. PMID: 27556178. DOI: 10.1002/hed.24571

Received June 4, 2020

Revised July 2, 2020

Accepted July 6, 2020 